\title{
Health-related quality of life in children with otitis media
}

\author{
Carole N.M. Brouwer ${ }^{a, b, 1}, A$. Rianne Maillé ${ }^{b, 2}$ \\ Maroeska M. Rovers ${ }^{b}$, Diederick E. Grobbee ${ }^{b, 2}$ \\ Elisabeth A.M. Sanders ${ }^{c}$, Anne G.M. Schilder ${ }^{d, *}$
}

\author{
${ }^{a}$ Department of Paediatrics, Spaarne Hospital Hoofddorp, Postbus 770, 2130 AT Hoofddorp, \\ The Netherlands \\ b Julius Center for Health Sciences and Primary Care, University Medical Center Utrecht, \\ P.O. Box 85500, 3508 GA Utrecht, The Netherlands \\ 'Department of Paediatric Immunology, Wilhelmina Children's Hospital/University Medical \\ Center Utrecht, P.O. Box 85090, 3508 AB Utrecht, The Netherlands \\ ${ }^{\mathrm{d}}$ Department of Otorhinolaryngology, Wilhelmina Children's Hospital/University Medical \\ Center Utrecht, KE.04.140.5, P.O. Box 85090, 3508 AB Utrecht, The Netherlands
}

Received 7 January 2005; accepted 11 March 2005

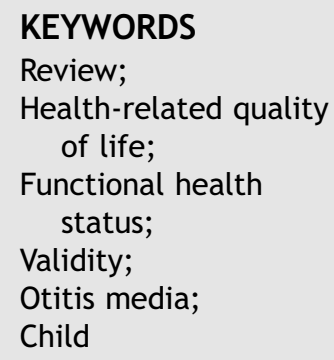

\begin{abstract}
Summary
Background: Growing interest in health-related quality of life (HRQoL) in children with otitis media has brought the need to study the currently available HRQoL instruments with respect to their results and their applicability in clinical practice and research of otitis media.

Objective: To review existing literature on health-related quality of life research in children with otitis media with respect to: (1) the measured impact of otitis media on HRQoL; and (2) the applicability of HRQoL instruments used in research and clinical practice based on their characteristics and contents.
\end{abstract}

Abbreviations: AOM, acute otitis media; Child QOL, OM-related Child Quality Of Life-visual analogue scale; EIS, Ear Infection Survey; FHS, functional health status; GIC-PPS, Grommet Insertion in Children-Prospective Parental Survey; HRQoL, health-related quality of life; OM, otitis media; OM-6, Otitis Media-6 items; OM7-27, Seven-Domain, 27-Item Questionnaire; OMO-22, Otitis Media Outcome-22 items; OM-CSI, Otitis Media Clinical Severity Index; OMD, Otitis Media Diary; OME, otitis media with effusion; OM-FSQ, Otitis Media Functional Status Questionnaire; PPSC, Play Performance Scale for Children; QoL, quality of life; QoL 3 item, Quality of Life-3 items; TAIQOL, TNO-AZL Infant Quality Of Life; VAS, visual analogue scale; VT, ventilation tube

* Corresponding author. Tel.: +31 3025040 04; fax: +31 302505348.

E-mail addresses: carol2b_workit@hotmail.com (Carole N.M. Brouwer), R.Maille@umcutrecht.nl (A.R. Maillé), M.M.Rovers@med.uu.nl (M.M. Rovers), D.Grobbee@azu.nl (D.E. Grobbee), L.Sanders@wkz.azu.nl (Elisabeth A.M. Sanders), A.Schilder@wkz.azu.nl (Anne G.M. Schilder).

${ }^{1}$ Present address: Julius Center for Health Sciences and Primary Care, Kramatweg 53-II, 1095 JW Amsterdam, The Netherlands. Tel.: +31204702724.

Tel.: +313025093 81; fax: +31302505485. 
Methods: A search was performed in EMBASE (1988-November 2004) and on NLM Gateway (1966-November 2004) for studies assessing health-related quality of life or functional health status by means of disease-specific or generic questionnaires in children aged $0-18$ years with chronic or recurrent otitis media with effusion or acute otitis media. The bibliographies of the selected articles were searched manually.

Results: Only 13 of the 141 retrieved articles retrieved fulfilled the criteria for inclusion. In these studies, physical suffering (pain, high fever, etc.), difficulties with hearing or speech, behavioural problems, or emotional distress were reported to be the most important problems experienced by children with otitis media. Almost all instruments applied in these studies measure functional health status instead of health-related quality of life. Data on validity and reliability of these instruments are incomplete.

Conclusions: Recurrent or chronic otitis media is reported to have a substantial and negative effect on various domains of functional health status and health-related quality of life of children. The OM- 6 appears to be the best available instrument to assess functional health status in children with $O M$ in a research setting. However, the lack of true HRQoL instruments as well as incomplete data on their reliability and validity, limit both our current knowledge of HRQoL in OM and the application of current instruments in both research and clinical practice.

(C) 2005 Elsevier Ireland Ltd. All rights reserved.

\section{Contents}

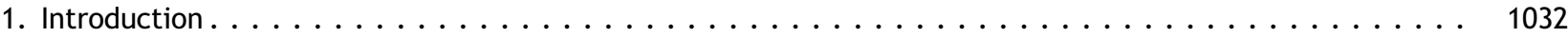



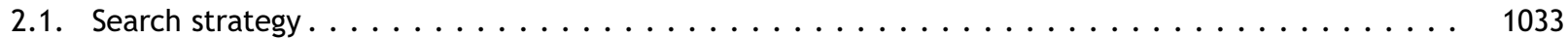

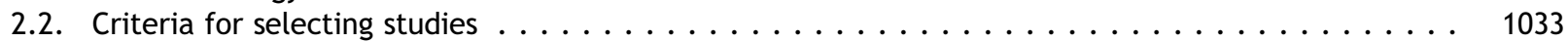

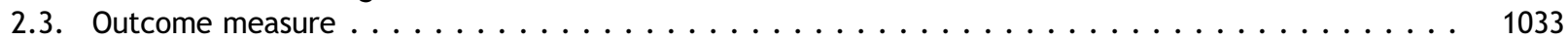

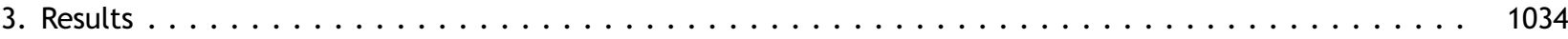

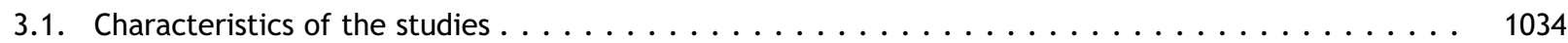

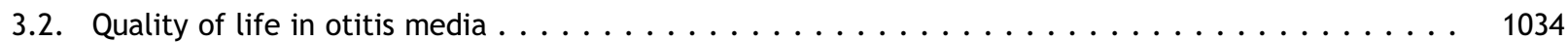

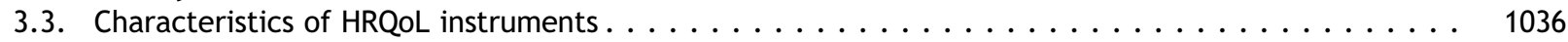

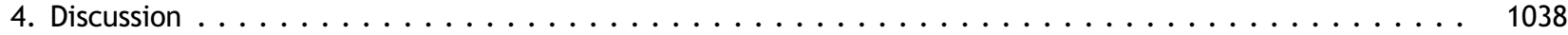

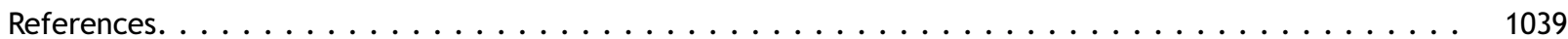

\section{Introduction}

Otitis media $(\mathrm{OM})$ is one of the most common disorders in childhood [1-3] and may have a considerable impact on health-related quality of life (HRQoL) [4-6] and functional health status (FHS) of children and their caregivers [7-20]. Whereas functional health status reflects the physical, psychological or emotional and social functioning of a child, health-related quality of life adds a valuation or affective response to this functioning. Up to now, most studies have focussed on the effects of $O M$ and its treatment on hearing, language and psychosocial development $[7,21-26]$. Only a few studies have addressed the broader scope of health-related quality of life as an outcome measure in OM [27-30]. Growing interest in HRQoL in children in general and those with $\mathrm{OM}$ in particular, however, has brought the need for knowledge of currently available HRQoL instruments and their applicability in clinical practice and research [14,31-34]. Haggard et al. have previously reviewed some important studies [28]. Their narrative review was part of a discussion on general issues regarding $\mathrm{HRQ} L \mathrm{~L}$ assessment in $\mathrm{OM}$, such as generic versus disease-specific instruments and scaling, and focussed on methodology. We aimed to perform a meta-analysis of the available studies on various HRQoL and FHS assessments in children with recurrent $\mathrm{OM}$, addressing both their methodology and outcome. Due to heterogeneity of the studies regarding population, follow-up, outcome measures and instruments used, pooling of the results in a meta-analysis proved impossible. Therefore, a systematic review was conducted, providing an overview of: (1) the effect of OM on HRQoL and FHS of children assessed with various HRQoL instruments; and (2) the applicability of these HRQoL instruments in research and clinical practice on the basis of their characteristics and contents. 


\section{Materials and methods}

\subsection{Search strategy}

A literature search was performed in EMBASE for articles dating from 1988 to November 2004 and on NLM Gateway from 1966 to November 2004, using the search terms that are proposed by EMBASE for otitis media ('otitis media' or 'chronic otitis media' or 'mucoid otitis media' or 'secretory otitis media' or 'serous otitis media') or 'acute otitis media' and 'quality of life' or 'health status' or 'functional status'. Search terms were entered as MESH headings as well as text or keywords. Limitations were age $(0-18$ years) and language (English, French and Dutch).

Additionally, a manual search of the bibliographies of these selected articles was done. Experts in the field were consulted. In case of obscurities or missing data, authors were contacted for supplementary information.

\subsection{Criteria for selecting studies}

Studies assessing health-related quality of life or functional health status by means of a disease-specific or a generic questionnaire (definitions are given in Table 1) in children aged $0-18$ years with chronic or recurrent otitis media with effusion (OME) or acute otitis media $(A O M)$, were considered: only those studies providing actual data through a HRQoL or FHS questionnaire or providing results of devel- opment or validation of such questionnaires, were included.

Review articles without original HRQoL data, articles that did not address HRQoL in OM, studies without presentation of HRQoL data or without the use of either a FHS or HRQoL questionnaire, non-human studies, and studies in adult populations were excluded. Inclusion and exclusion was based on screening of titles and abstracts, in case of obscurities, the full-text article was examined.

\subsection{Outcome measure}

The studies were systematically assessed according to the following topics:

I. General characteristics of the study: setting; type of patients included; mean age and agerange of the patients.

II. Outcome of the study: effects of OM on HRQoL of a child.

III. Characteristics of HRQoL instruments: assessment of FHS versus HRQoL; generic versus disease-specific questionnaires (see Table 1); reporter; scoring; scale; number of items; domains that are addressed (physical symptoms, emotional functioning, social functioning, other domains); psychometric characteristics (reliability and validity).

Although $A O M$, recurrent $A O M$ and chronic $O M E$ are related conditions, we decided to discuss the influence of each condition on HRQoL separately.

Table 1 Definitions of health-related quality of life, functional health status and instrument types

\begin{tabular}{|c|c|}
\hline Health-related quality of life & $\begin{array}{l}\text { Level of satisfaction of a person with those aspects of his } \\
\text { or her life that are affected by the effects of an illness } \\
\text { and its treatment [7-11]. Measures of HRQoL should } \\
\text { incorporate perceptions of physical, psychological or } \\
\text { emotional and social functioning [9,11]. Incorporation } \\
\text { of a person's valuation of his life distinguishes HRQoL } \\
\text { from other measures of well-being [12-17] }\end{array}$ \\
\hline Functional health status & $\begin{array}{l}\text { Combination of health status reflecting the (severity of) } \\
\text { signs and symptoms of disease, and functional status } \\
\text { reflecting the adequacy of an individual's daily functioning } \\
\text { across various life-domains [14-17] }\end{array}$ \\
\hline Generic instruments & $\begin{array}{l}\text { Are applicable to people in different health states and with } \\
\text { different medical conditions. They cover a wide range of } \\
\text { health-related functioning (mental, physical, and psychosocial). } \\
\text { Consequently, the results of generic questionnaires are } \\
\text { comparable across different patient groups }[9,17-19]\end{array}$ \\
\hline Disease-specific instruments & $\begin{array}{l}\text { Focus on aspects of HRQoL relevant to a specific illness. } \\
\text { Therefore, they are much more likely to detect subtle, } \\
\text { yet clinically relevant health issues in the patient's } \\
\text { HRQoL and are more responsive to change }[8,18-20]\end{array}$ \\
\hline
\end{tabular}




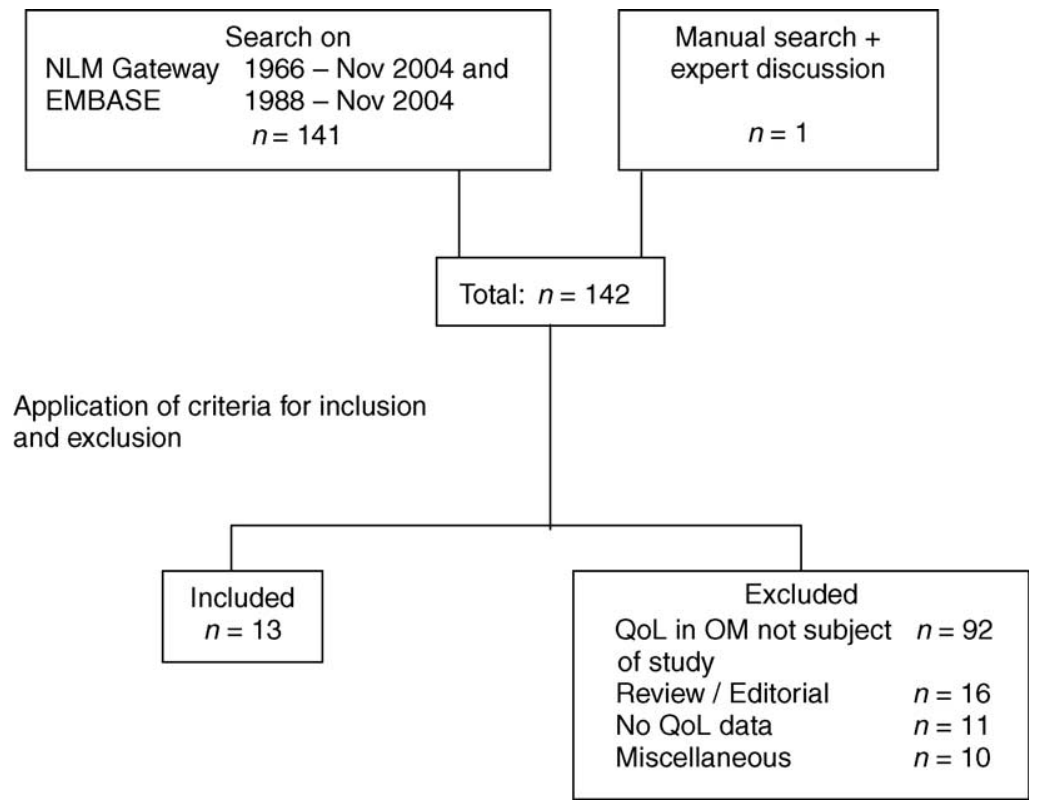

Fig. 1 Results of search strategy.

\section{Results}

The search resulted in 141 citations. The manual search and expert discussion yielded one extra article [28]. After applying the criteria for inclusion and exclusion, only 13 articles remained for inclusion [29,30,35-44]. In addition, we included results regarding reliability and validity of the TAIQOL from our own work published in a thesis [45]. Ninety-two articles were excluded because QoL in OM was not the subject of study, 16 were review articles or editorial comments, in 11 articles no QoL data were presented, and 10 articles were excluded for various reasons (Fig. 1).

\subsection{Characteristics of the studies}

The setting of the studies varied, eight studies were part of a multi-centre trial $[28,35,37,38,41,43-45]$. Most study-populations consisted of children with chronic or recurrent otitis media (Table 2 ). The definitions of chronic and recurrent $O M$ regarding number of $\mathrm{OM}$ episodes and duration, however, varied considerably. Chronic OME was defined as middle ear effusion in one or both ears for 6 weeks [36] to 6 months [41], rAOM as three or more episodes in previous 6 months $[36,38,43]$ or more than three $[29,45]$ to five [42] episodes within last year. Age of the patients ranged from 0 to 13 years of age. The majority of children, however, were younger than 3 years of age at inclusion.

\subsection{Quality of life in otitis media}

Asmussen et al. [35] found that more than $50 \%$ of the caregivers experienced physical problems on the part of their child, such as difficulty in sleeping, poor eating, irritability or fussiness, as a consequence of rAOM and chronic OME. Rosenfeld et al. $[29,38]$ found physical suffering (e.g. ear pain or discomfort, high fever, poor balance), hearing loss and emotional distress to be prominent in children with $\mathrm{rAOM}$ and chronic OME, especially in those admitted for ventilation tube (VT) insertion. Similar results were found by Greenberg et al. [43]. Children with rAOM and chronic OME referred for VT placement in a study by Richards and Giannoni [42] scored significantly poorer on an OM-related questionnaire (OM-22) than children without a significant history of ear problems. Hearing and vestibular symptoms, speech and social effects were most severely affected.

Alsarraf et al. [30] reported that children suffering from an episode of acute otitis media scored significantly worse than healthy children did on all clinical and functional measures. Those who had recovered from AOM continued to score two to four times worse on these measurements compared to healthy controls during 6-12 weeks of follow-up. Bertin et al. [37] reported sleep and appetite to be moderate to severely affected at the start of an acute episode of OM.

In children admitted for bilateral VT insertion for OME, Karkanevatos and Lesser [40] found that the 
Table 2 Results of studies on QoL in children with otitis media

\begin{tabular}{|c|c|c|c|c|}
\hline Study & Instrument & Patients $(n)$ and condition & Age (range) & Study outcome (Child QOL) \\
\hline Asmussen et al. [35] & EIS & $65^{\mathrm{a}} \mathrm{cOME} / \mathrm{rAOM}$ & 1.5 years $(0-3$ years $)$ & $\begin{array}{l}>50 \% \text { difficulty in sleeping, poor eating, } \\
\text { frequent fevers, unusually irritable or fussy }\end{array}$ \\
\hline Gupta et al. [36] & & & & $\begin{array}{l}\text { Score on physical, mental and social domain } \\
\text { significantly lower in moderate to severe OM } \\
\text { than in mild OM }\end{array}$ \\
\hline Bertin et al. [37] & QoL 3 item & 219 AOM & (1-6 years) & $\begin{array}{l}\text { On average, appetite and sleep were moderate } \\
\text { to severely affected, playing activity was } \\
\text { less affected }\end{array}$ \\
\hline Rosenfeld et al. [29] & $\begin{array}{l}\text { OM-6, NRS } \\
\text { ear-related QoL }\end{array}$ & $186 \mathrm{cOME} / \mathrm{rAOM}$ & $\begin{array}{l}3.4 \text { years } \\
(6 \text { months }-12 \text { years })\end{array}$ & $\begin{array}{l}\text { Very much extreme a problem: physical suffering } \\
\text { in } 16 \% \text {, hearing loss } 11 \% \text {, emotional distress } 6 \% \text {, } \\
\text { activity limitations } 5 \% \text {, speech impairment } 8 \% \\
\text { Median score } 7 \text { out of } 10\end{array}$ \\
\hline Rosenfeld et al. [38] & OM-6 & $248 \mathrm{cOME} / \mathrm{rAOM}$ & $\begin{array}{l}1.4 \text { years } \\
(0.5 \text { months }-9.9 \text { years })\end{array}$ & $\begin{array}{l}\text { Very much extreme a problem: physical suffering } \\
\text { in } 37 \% \text { (admitted for VT), emotional distress } 24 \% \text {, } \\
\text { activity limitations } 12 \% \text {, hearing loss } 9 \% \text {, and } \\
\text { speech impairment } 9 \%\end{array}$ \\
\hline Timmerman et al. [39] & OM-6 & 77 cOME & $(1-3$ years $)$ & $\begin{array}{l}\text { Caregiver concern and speech impairment highest } \\
\text { rated problems, followed by physical suffering, } \\
\text { hearing loss, emotional distress, activity limitations }\end{array}$ \\
\hline Karkanevatos and Lesser [40] & GIC-PPS & 150 cOME & 4 years (1-6 years) & $\begin{array}{l}\text { Year before VT: } 76 \% \text { had episodes of earache, } \\
\text { problems with sleeping in } 64 \% \text {, behaviour } 49 \% \text {, } \\
\text { hearing } 33-62 \% \text {, speech } 37 \% \text {, balance } 15 \%\end{array}$ \\
\hline Alsarraf et al. [30] & $\begin{array}{l}\text { OM-SCI, OMD, } \\
\text { OM-FSQ, PPSC }\end{array}$ & $\begin{array}{l}25 \mathrm{AOM}, 26 \\
\text { well-child controls }\end{array}$ & (1-3 years) & $\begin{array}{l}\text { All scores significantly lower in AOM than in } \\
\text { healthy controls ( } p<0.001) \\
\text { Scores two to four times lower after recovery } \\
\text { of AOM compared to healthy controls }\end{array}$ \\
\hline Haggard et al. [28] & $\begin{array}{l}\text { OM7-27, } \\
\text { Child QOL }\end{array}$ & $\begin{array}{l}224 \text { cOME, } 709 \\
\text { well-child controls }\end{array}$ & (3-9 years) & $\begin{array}{l}\text { Score in OME significantly, but modestly lower } \\
\text { than in healthy controls }\end{array}$ \\
\hline Rovers et al. [41] & $\begin{array}{l}\text { TAIQOL, } \\
\text { Erickson scales }\end{array}$ & 187 COME & 19.5 months & $\begin{array}{l}\text { Domains communication, motoric, aggression, } \\
\text { and sleeping most severely affected } \\
\text { Parent-child interaction slightly poorer than in } \\
\text { reported in healthy children }\end{array}$ \\
\hline
\end{tabular}




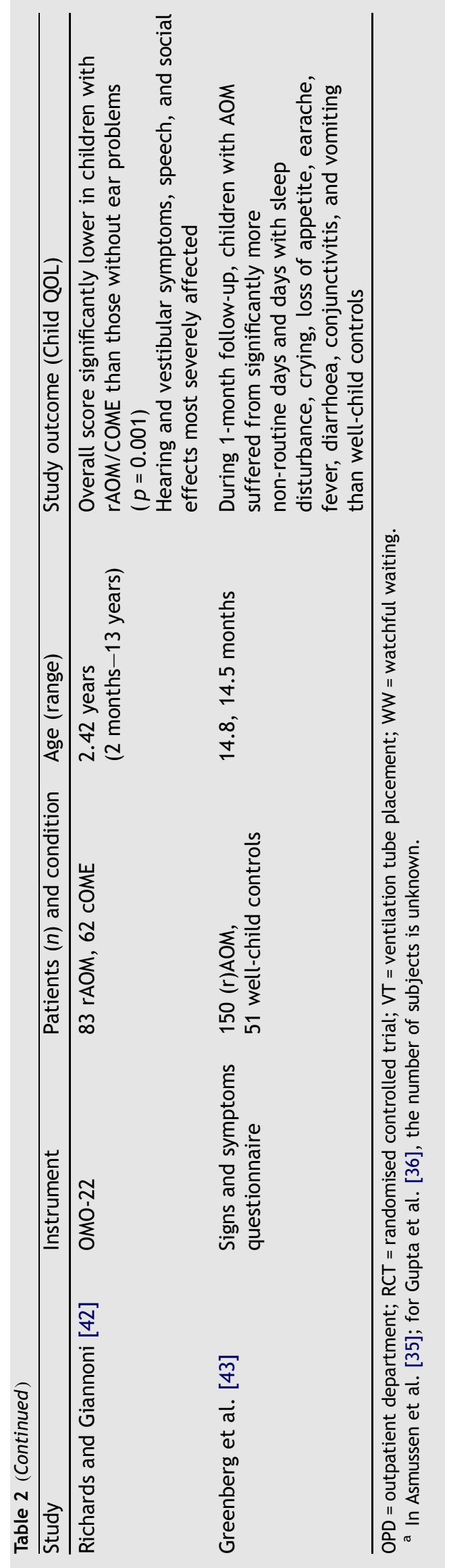

majority suffered from disturbed sleep. Behavioural problems at school or nursery, as well as difficulties with hearing, speech, and to a less extent, balance, were also common. Furthermore, caregivers of children with persistent bilateral OME randomized to a watchful waiting approach reported slightly more problems regarding communication, motor functioning, problem behaviour, and sleeping as well as than parents of children randomized to insertion of ventilation tubes. Besides, the parent-child interaction scores in children with persistent OME were also slightly poorer than had been observed in children without disease [41].

\subsection{Characteristics of HRQoL instruments}

In 13 studies, 15 different questionnaires were used to measure HRQoL (Table 2). Only the nine instruments, for which data regarding their reliability or validity were available, are discussed here (Tables 3 and 4). Except for the TAIQOL, all questionnaires address FHS and not HRQoL as such. The TAIQOL is the only true generic HRQoL questionnaire used in these studies: in addition to a score for severity of symptoms or functioning, it includes valuation by a caregiver of the FHS of a child when experiencing signs or symptoms of a disease. Unfortunately, norm scores are not available yet. The NRS-global earrelated QoL and the CQOL are direct one-item global scales of HRQoL (numerical rating and visual analogue scale, respectively), the other questionnaires use indirect Likert scales. All instruments, with exception of the OM-CSI, which is a physician-completed instrument, are completed by caregivers. Only five questionnaires (EIS, OM-6, OM-FSQ, TAIQOL, OMO-22) include items from all three areas of functioning (physical, emotional, social), whereas two questionnaires (EIS, OM-6) also address caregiver or family functioning (Table 3).

Table 4 shows the psychometrics of the various identified QoL instruments. To assess HRQoL, instruments need to be reliable and valid. One aspect of reliability is internal consistency, i.e. the homogeneity and coherence of the items of an instrument. As the most popular method to assess internal consistency, Cronbach's $\alpha$ has been calculated in all occasions and, except for some TAIQOL subscales, generally reflected good internal consistency. Few studies assessed another aspect of reliability: reproducibility, i.e. the ability to reproduce the same results when nothing has changed. Reproducibility of the OM- 6 and TAIQOL, assessed by test-retest reliability, was good for both instruments. For the PPSC, inter-rater reliability has been assessed, which was moderate. 
Table 3 Characteristics of QoL instruments used in assessment of QoL in children

\begin{tabular}{|c|c|c|c|}
\hline & Type & Score (number of items) & Topics \\
\hline EIS $[35,36]$ & FHS ds & N.A. (6) & $\begin{array}{l}\text { Physical: physical health } \\
\text { Emotional: emotional health (child) } \\
\text { Social: social activity (child) } \\
\text { Other: emotional health, social activity (family) }\end{array}$ \\
\hline OM-6 $[29,38,39,44]$ & FHS ds & Subdomain total (6) & $\begin{array}{l}\text { Physical: physical suffering, hearing loss, speech } \\
\text { Emotional: emotional distress } \\
\text { Social: activity limitations } \\
\text { Other: caregiver concerns }\end{array}$ \\
\hline $\begin{array}{l}\text { NRS ear-related } \\
\text { QOL [29] }\end{array}$ & HRQoL ds & Global 1 item (1) & Other: global rating of child HRQoL \\
\hline OM-CSI [30] & FHS ds & Total (10) & $\begin{array}{l}\text { Physical: fever at home, ear pain, temperature, } \\
\text { tympanic membrane examination } \\
\text { Emotional: irritability }\end{array}$ \\
\hline OMD [30] & FHS ds & Total (3) & Idem to OM-CSI \\
\hline OM-FSQ [30] & \{FHS gen & Total (14) & $\begin{array}{l}\text { Physical: eating, sick and tired, sleeping } \\
\text { Emotional: mood, emotional distress, behaviour } \\
\text { Social: response to environment, occupying self } \\
\text { Physical: episodes of OM, ear pain, sleeping }\end{array}$ \\
\hline PPSC $[30,50]$ & FHS gen & Global 1 item (1) & Other: overall quality and vigour of play behaviour \\
\hline OM7-27 [28] & FHS ds & Total subdomain (27) & $\begin{array}{l}\text { Physical: hearing, respiratory tract symptoms, } \\
\text { sleeping, global physical health, speech/language } \\
\text { Emotional: behaviour } \\
\text { Other: ENT-related parent QoL }\end{array}$ \\
\hline Child QOL [28] & HRQoL ds & Global 1 item (1) & Other: global rating of child's HRQoL \\
\hline TAIQOL $[41,45,48]$ & HRQoL gen & Subdomain total (46) & $\begin{array}{l}\text { Physical: physical health, sleeping, appetite, } \\
\text { motor functioning, communication }{ }^{\text {a }} \\
\text { Emotional: mood, anxiety, behaviour } \\
\text { Social: social functioning }\end{array}$ \\
\hline OMO-22 [42] & FHS ds & $\begin{array}{l}\text { Item subdomain } \\
\text { total }(22)\end{array}$ & $\begin{array}{l}\text { Physical: ear discomfort, fever, sleeping, balance, } \\
\text { hearing, language, speech } \\
\text { Emotional: mood, emotional distress, behaviour } \\
\text { Social: play, social activities, } \\
\text { school/daycare attendance }\end{array}$ \\
\hline
\end{tabular}

HRQoL = health-related quality of life; FHS = functional health status; ds = disease-specific; gen = generic; N.A. = not available.

a Items about speech and language capacity.

The construct validity, i.e. the degree to which an instrument measures the concept it is supposed to measure $[16,22,46,47]$, was assessed by comparing mean (subscale) scores with physician-rated clinical severity, functional severity or other clinical symptoms, and found to be moderate to high. The discriminant validity is another, rough method to evaluate construct validity by comparing instrument results between two groups on the extreme, i.e. one with the trait or condition and one without [49]. The OM-CSI, OM-FSQ, OMD, PPSC $[30,50]$ and the OM-22 [42] differentiated well between children with and without ear problems. The discriminant validity of the TAIQOL was less satisfying: it did discriminate between healthy children from a general population versus preterm children as well as children with versus children without a chronic disease, but not between children with differing frequency of AOM episodes $(2-3$ per year versus $\geq 4$ per year) $[45,48]$. The multitrait-multimethod approach has not been applied in any of these studies [49].

Finally, to evaluate treatment effects, HRQoL instruments need to be responsive, i.e. they should be able to detect clinically important change over time [49]. Unfortunately, responsiveness has been assessed for six instruments only. The responsiveness of the OM- 6 has been evaluated by standardized response means and found to be very good, but may have been flattered by the fact that parents were not blinded to the intervention [29,39]. Alsarraf 
Table 4 Psychometrics of the identified QoL instruments

\begin{tabular}{|c|c|c|c|c|}
\hline & IC (Cronbach's $\alpha$ ) & Reproducibility $(R)$ & Construct validity & Responsiveness \\
\hline EIS $[35,36]$ & $0.70-0.88$ & N.A. & \pm & N.A. \\
\hline OM-6 $[29,38,39,44]$ & 0.79 & 0.87 & + & + \\
\hline OM-CSI [30] & 0.94 & N.A. & + & + \\
\hline OMD [30] & 0.89 & N.A. & + & + \\
\hline OM-FSQ [30] & 0.96 & N.A. & + & + \\
\hline PPSC $[30,50]$ & N.A. & $0.42-0.74$ & ++ & + \\
\hline OM7-27 [28] & N.A. & $\geq 0.73$ & N.A. & N.A. \\
\hline TAIQOL $[45,48]$ & $\begin{array}{l}0.66-0.88^{a} \\
0.43-0.84^{b} \\
0.72-0.90^{c}\end{array}$ & $0.76-0.90$ & \pm & - \\
\hline OMO-22 [42] & 0.85 & N.A. & + & N.A. \\
\hline
\end{tabular}

et al. [30] have reported a good responsiveness for the OM-CSI, OM-FSQ, OMD and PPSC. The TAIQOL subscales assessing ear-related problems showed a poor sensitivity to change [45].

\section{Discussion}

In recent years, various studies have aimed to assess health-related quality of life in children with $\mathrm{OM}$. Some of them have been reviewed previously as part of a general discussion of methodological issues in HRQoL assessment in children with OM [28]. This is the first systematic review of both methodology and outcomes of HRQoL assessment in OM. Heterogeneity of the studies precluded pooling of results in a meta-analysis.

The negative impact of AOM on the child's functioning appeared to be substantial and similar between the studies in this review, with the majority of children with $A O M$ reported to experience physical suffering (pain, high fever, disturbed sleep, etc.), difficulty with hearing or speech, behavioural problems or emotional distress. In OME, hearing, speech, behavioural, and balance problems were most prominent.

These results correspond largely with previous epidemiological and diagnostic studies of physical symptoms in AOM [51-54] and OME [21,22,24, 25,55-58]. They thus support the notion that, except for the TAIQOL, the so-called HRQoL instruments used in children with OM so far address only symptoms and functioning of the child and thus in fact measure FHS. Questions exploring feelings or perceptions towards their health status, essential to HRQoL assessment, are missing. In addition, the instruments focus on physical and behavioural aspects of FHS; only a few address emotional or social symptoms and functioning in $\mathrm{OM}$.

It becomes clear that similar problems are faced in HRQoL studies in children with $\mathrm{OM}$ as in studies on HRQoL in children with other medical conditions $[7,12,59]$. First, as children have limited cognitive and language abilities, most studies rely either on (observable) measures that are assumed to be related to HRQoL, but actually reflect FHS, or they rely on caregivers as proxies. There is considerable discussion about the appropriateness of caregivers assessing HRQoL in children [11,60-64]. It appears that caregivers are more capable to judge the child's HRQoL in terms of physical functioning, rather than less observable aspects such as the child's emotional or social functioning [65]. Besides, one may wonder whether the HRQoL of a child as judged by caregivers is not merely a reflection of caregiver worries and emotional stress, which appear to be considerable $[4,5]$. In none of the studies, however, possible relations between caregiver reports of $\mathrm{HRQ}$ oL in their children and level of caregiver worries or disruption have been explored.

For most instruments included in this review, there is no convincing evidence regarding their reliability and validity. Although for 9 out of the 15 instruments, some assessment of their reliability and validity has been performed, none of them has been evaluated sufficiently to justify general use in clinical trials. Especially, the lack of data regarding reproducibility and responsiveness limits comparison of HRQoL in different populations and evaluation of the natural course of the condition and effects of treatment. Future studies that focus on effects of treatment of $O M$ need to address this insufficiency of currently used instruments, applying recent guidelines regarding use of multiple 
methods and interpretation of change [66-69]. Based on its content and reported reliability and validity, we recommend the $0 \mathrm{M}-6$ as the most appropriate instrument currently available for FHS assessment in children with $O M$ in a research setting, bearing in mind that the OM-6 was originally designed to evaluate change, and not to discriminate between populations. Although based on content validity the TAIQOL appeared to be promising, its disappointing construct validity and responsiveness renders it less useful. Therefore, we believe that currently there is no adequate instrument available for valid HRQoL assessment in children with otitis media. Furthermore, none of the available instruments reached adequate reliability for clinical assessment of $\mathrm{HRQ}$ oL in individual patients.

In conclusion, the impact of OM on quality of life in children seems substantial and $O M$ affects various aspects of the child's functioning. Our true knowledge, however, of HRQoL in children with recurrent or chronic $O M$ is still limited, since up to now widely different instruments have been used to assess wellbeing in children with recurrent $O M$ and most of them actually measure FHS rather than HRQoL. Furthermore, data on reliability and validity of these instruments are insufficient and current HRQoL instruments are not adequate for assessments in individual patients. Therefore, currently HRQoL can only be assessed in children with OM on a population level whereby we recommend that clinicians: (1) use a combination of generic and diseasespecific instruments to allow for comparisons between HRQoL of children with $\mathrm{rAOM}$ and that of healthy children or children with other medical conditions; (2) use a limited number of instruments with adequate reliability and discriminant validity; (3) validate these instruments in a pilot study; and (4) use instruments that include emotional and social functioning and add a valuation or affective response to the child's functioning.

\section{References}

[1] D.W. Teele, J.O. Klein, B. Rosner, Epidemiology of otitis media during the first seven years of life in children in greater Boston: a prospective, cohort study, J. Infect. Dis. 160 (1989) 83-94.

[2] H. Faden, L. Duffy, M. Boeve, Otitis media: back to basics, Pediatr. Infect. Dis. J. 17 (1998) 1105-1112.

[3] K.A. Daly, G.S. Giebink, Clinical epidemiology of otitis media, Pediatr. Infect. Dis. J. 19 (2000) S31-S36.

[4] L. Asmussen, L.M. Olson, S.A. Sullivan, 'You have to live it to understand it...'-family experiences with chronic otitis media in children, Ambul. Child Health 5 (1999) 303-312.

[5] S.C. Smith, M.P. Haggard, The MRC Multicentre Otitis Media Study Group, Communication tactics used by parents of children with OME (glue ear), Psychol. Health Med. 4 (4) (1999) 333-344.

[6] J.O. Klein, The burden of otitis media, Vaccine 19 (Suppl. 1) (2000) S2-S8.

[7] C. Eiser, Children's quality of life measures, Arch. Dis. Child. 77 (1997) 350-354.

[8] G.H. Guyatt, C.D. Naylor, E. Juniper, D.K. Heyland, R. Jaeschke, D.J. Cook, Users' guides to the medical literature. XII. How to use articles about health-related quality of life. Evidence-Based Medicine Working Group, J. Am. Med. Assoc. 277 (1997) 1232-1237.

[9] M.E. Jenney, S. Campbell, Measuring quality of life, Arch. Dis. Child. 77 (1997) 347-350.

[10] E.F. Juniper, Quality of life in adults and children with asthma and rhinitis, Allergy 52 (1997) 971-977.

[11] N.C. Theunissen, T.G. Vogels, H.M. Koopman, G.H. Verrips, K.A. Zwinderman, S.P. Verloove-Vanhorick, et al. The proxy problem: child report versus parent report in health-related quality of life research, Qual. Life Res. 7 (1998) 387-397.

[12] T.M. Gill, A.R. Feinstein, A critical appraisal of the quality of quality-of-life measurements, J. Am. Med. Assoc. 272 (1994) 619-626.

[13] H. Schipper, J.J. Clinch, CL.M. Olweny, Quality of life studies: definitions and conceptual issues, in: B. Spilker (Ed.), Quality of Life and Pharmacoeconomics in Clinical Trials, Lippincot-Raven Publishers, Philadelphia, USA, 1996, pp. 11-23.

[14] M. Bergner, Quality of life, health status, and clinical research, Med. Care 27 (1989) S148-S156.

[15] M. Bullinger, U. Ravens-Sieberer, Health related quality of life assessment in children: a review of the literature, Rev. Eur. Psychol. Appl. 45 (4) (1995) 245-254.

[16] M.F. Muldoon, S.D. Barger, J.D. Flory, S.B. Manuck, What are quality of life measurements measuring? Br. Med. J. 316 (1998) 542-545.

[17] B.M. Feldman, B. Grundland, L. McCullough, V. Wright, Distinction of quality of life, health related quality of life, and health status in children referred for rheumatologic care, J. Rheumatol. 27 (2000) 226-233.

[18] E.F. Juniper, Impact of upper respiratory allergic diseases on quality of life, J. Allergy Clin. Immunol. 101 (1998) S386S391.

[19] A. Erling, Methodological considerations in the assessment of health-related quality of life in children, Acta Paediatr. Suppl. 88 (1999) 106-107.

[20] M.G. Stewart, Pediatric outcomes research: development of an outcomes instrument for tonsil and adenoid disease, Laryngoscope 110 (2000) 12-15.

[21] J. Lous, Otitis media and reading achievement: a review, Int. J. Pediatr. Otorhinolaryngol. 32 (1995) 105-121.

[22] J.S. Gravel, I.F. Wallace, Language, speech, and educational outcomes of otitis media, J. Otolaryngol. 27 (Suppl. 2) (1998) 17-25.

[23] J.S. Gravel, I.F. Wallace, Effects of otitis media with effusion on hearing in the first 3 years of life, J. Speech Lang. Hear. Res. 43 (2000) 631-644.

[24] D.L. Johnson, P.R. Swank, M.J. Owen, C.D. Baldwin, V.M. Howie, D.P. McCormick, Effects of early middle ear effusion on child intelligence at three, five, and seven years of age, J. Pediatr. Psychol. 25 (2000) 5-13.

[25] J.L. Paradise, C.A. Dollaghan, T.F. Campbell, H.M. Feldman, B.S. Bernard, D.K. Colborn, et al. Language, speech sound production, and cognition in three-year-old children in relation to otitis media in their first three years of life, Pediatrics 105 (2000) 1119-1130.

[26] J.L. Paradise, H.M. Feldman, T.F. Campbell, C.A. Dollaghan, D.K. Colborn, B.S. Bernard, et al. Effect of early or delayed 
insertion of tympanostomy tubes for persistent otitis media on developmental outcomes at the age of three years, N. Engl. J. Med. 344 (2001) 1179-1187.

[27] N. Facione, Quality of life issues in chronic otitis media with effusion: parameters for future study, Int. J. Pediatr. Otorhinolaryngol. 22 (1991) 167-179.

[28] M.P. Haggard, S.C. Smith, E.E. Nicholls, Quality of life and child behavior, in: R.M. Rosenfeld, C.D. Bluestone (Eds.), Evidence-Based Otitis Media, BC Decker Inc., Hamilton, Canada, 2003, pp. 400-428.

[29] R.M. Rosenfeld, A.J. Goldsmith, L. Tetlus, A. Balzano, Quality of life for children with otitis media, Arch. Otolaryngol. Head Neck Surg. 123 (1997) 1049-1054.

[30] R. Alsarraf, C.J. Jung, J. Perkins, C. Crowley, G.A. Gates, Otitis media health status evaluation: a pilot study for the investigation of cost-effective outcomes of recurrent acute otitis media treatment, Ann. Otol. Rhinol. Laryngol. 107 (1998) 120-128.

[31] P. Rosenbaum, D. Cadman, H. Kirpalani, Pediatrics: assessing quality of life, in: B. Spilker (Ed.), Quality of Life Assessments in Clinical Trials, Raven Press Ltd., New York, 1990, pp. 205-214.

[32] S. Dedhiya, S.X. Kong, Quality of life: an overview of the concept and measures, Pharm. World Sci. 17 (1995) 141148.

[33] M.P. Tully, J.A. Cantrill, Subjective outcome measurementa primer, Pharm. World Sci. 21 (1999) 101-109.

[34] M. Dijkers, Measuring quality of life: methodological issues, Am. J. Phys. Med. Rehabil. 78 (1999) 286-300.

[35] L. Asmussen, S.A. Sullivan, L.M. Olson, G.V. Fleming, The "Ear Infection Survey": a condition-specific functional outcomes measure for families of children with chronic otitis media, AHSR FHSR Annu. Meet. Abstr. Book 13 (1996) 14 (Abstract).

[36] K.Y. Gupta, L. Asmussen, L.M. Olson, The Ear Infection Survey (EIS): psychometric testing of a functional status measure for young children with otitis media, Abstr. Book Assoc. Health Serv. Res. 16 (1999) 346-347 (Abstract).

[37] L. Bertin, G. Pons, P. d'Athis, J.F. Duhamel, C. Maudelonde, G. Lasfargues, et al. A randomized, double-blind, multicentre controlled trial of ibuprofen versus acetaminophen and placebo for symptoms of acute otitis media in children, Fundam. Clin. Pharmacol. 10 (1996) 387-392.

[38] R.M. Rosenfeld, M.H. Bhaya, C.M. Bower, P.E. Brookhouser, M.L. Casselbrant, K.H. Chan, et al. Impact of tympanostomy tubes on child quality of life, Arch. Otolaryngol. Head Neck Surg. 126 (2000) 585-592.

[39] A.A. Timmerman, L.J. Anteunis, C.M. Meesters, Responseshift bias and parent-reported quality of life in children with otitis media, Arch. Otolaryngol. Head Neck Surg. 129 (2003) 987-991.

[40] A. Karkanevatos, T.H. Lesser, Grommet insertion in children: a survey of parental perceptions, J. Laryngol. Otol. 112 (1998) 732-741.

[41] M.M. Rovers, P.F. Krabbe, H. Straatman, K. Ingels, G.J. van der Wilt, G.A. Zielhuis, Randomised controlled trial of the effect of ventilation tubes (grommets) on quality of life at age 1-2 years, Arch. Dis. Child. 84 (2001) 4549.

[42] M. Richards, C. Giannoni, Quality-of-life outcomes after surgical intervention for otitis media, Arch. Otolaryngol. Head Neck Surg. 128 (2002) 776-782.

[43] D. Greenberg, N. Bilenko, Z. Liss, T. Shagan, O. Zamir, R. Dagan, The burden of acute otitis media on the patient and the family, Eur. J. Pediatr. 162 (9) (2003) 576-581.

[44] H. Kubba, I.R.C. Swan, S. Gatehouse, How appropriate is the OM6 as a discriminative instrument in children with otitis media? Arch. Otolaryngol. Head Neck Surg. 130 (2004) 705709.

[45] C.N.M. Brouwer, Health related quality of life in children with recurrent acute otitis media, Thesis, Julius Center for Health Sciences and Primary Care, University Medical Center, Utrecht, The Netherlands, 2003, pp. 47-95.

[46] M.E. Hyland, The validity of health assessments: resolving some recent differences, J. Clin. Epidemiol. 46 (1993) 1019-1023.

[47] R.D. Hays, R.T. Anderson, D.A. Revicki, Assessing reliability and validity of measurement in clinical trials, in: M.J. Staquet, R.D. Hays, P.M. Fayers (Eds.), Quality of Life Assessment in Clinical Trials, first ed., Oxford University Press, Oxford, UK, 1998, pp. 169-182.

[48] M. Fekkes, N.C. Theunissen, E. Brugman, S. Veen, E.G. Verrips, H.M. Koopman, et al. Development and psychometric evaluation of the TAPQOL: health-related quality of life instrument for 1-5-year-old children, Qual. Life Res. 9 (2000) 961-972.

[49] D.L. Streiner, G.R. Norman, Health Measurement Scales-A Practical Guide to Their Development and Use, second ed., Oxford University Press, New York, USA, 2001.

[50] R.K. Mulhern, D.L. Fairclough, A.G. Friedman, L.D. Leigh, Play performance scale as an index of quality of life of children with cancer, Psychol. Assess.: J. Consult. Clin. Psychol. 2 (2) (1990) 149-155.

[51] O. Ruuskanen, T. Heikkinen, Otitis media: etiology and diagnosis, Pediatr. Infect. Dis. J. 13 (1994) S23-S26.

[52] T. Heikkinen, O. Ruuskanen, Signs and symptoms predicting acute otitis media, Arch. Pediatr. Adolesc. Med. 149 (1995) 26-29.

[53] T. Kontiokari, P. Koivunen, M. Niemela, T. Pokka, M. Uhari, Symptoms of acute otitis media, Pediatr. Infect. Dis. J. 17 (1998) 676-679.

[54] C.D. Bluestone, Clinical course, complications and sequelae of acute otitis media, Pediatr. Infect. Dis. J. 19 (2000) S37S46.

[55] M.L. Casselbrant, J.M. Furman, E. Rubenstein, E.M. Mandel, Effect of otitis media on the vestibular system in children, Ann. Otol. Rhinol. Laryngol. 104 (1995) 620-624.

[56] A. Golz, B. Angel-Yeger, S. Parush, Evaluation of balance disturbances in children with middle ear effusion, Int. J. Pediatr. Otorhinolaryngol. 43 (1998) 21-26.

[57] J.E. Robert, M.R. Burchinal, L.P. Medley, S.A. Zeisel, M. Mundy, J. Roush, et al. Otitis media, hearing sensitivity, and maternal responsiveness in relation to language during infancy, J. Pediatr. 126 (1995) 481-489.

[58] K.E. Bennett, M.P. Haggard, Behaviour and cognitive outcomes from middle ear disease, Arch. Dis. Child. 80 (1999) $28-35$.

[59] J.M. Landgraf, E. Maunsell, K.N. Speechley, M. Bullinger, S. Campbell, L. Abetz, et al. Canadian-French, German and UK versions of the Child Health Questionnaire: methodology and preliminary item scaling results, Qual. Life Res. 7 (1998) 433-445.

[60] M. Sawyer, G. Antoniou, I. Toogood, M. Rice, A comparison of parent and adolescent reports describing the health-related quality of life of adolescents treated for cancer, Int. J. Cancer Suppl. 12 (1999) 39-45.

[61] M. Wake, K. Hesketh, F. Cameron, The Child Health Questionnaire in children with diabetes: cross-sectional survey of parent and adolescent-reported functional health status, Diabet. Med. 17 (2000) 700-707.

[62] M.M. Weissman, H. Orvaschel, N. Padian, Children's symptom and social functioning self-report scales. Comparison of mothers' and children's reports, J. Nerv. Ment. Dis. 168 (1980) 736-740. 
[63] J.M. Cunningham, E.J. Chiu, J.M. Landgraf, R.E. Gliklich, The health impact of chronic recurrent rhinosinusitis in children, Arch. Otolaryngol. Head Neck Surg. 126 (2000) 1363-1368.

[64] C. Eiser, R. Morse, Can parents rate their child's healthrelated quality of life?. Results of a systematic review Qual. Life Res. 10 (2001) 347-357.

[65] C. Eiser, R. Morse, Quality-of-life measures in chronic diseases of childhood, Health Technol. Assess. 5 (2001) 1157.

[66] Scientific Advisory Committee of the Medical Outcomes Trust, Assessing health status and quality of life instruments: attributes and review criteria, Qual. Life Res. 11 (2002) 193-205.

[67] G.H. Guyatt, D. Osaba, A.W. Wu, K.W. Wyrwich, G.R. Norman, Methods to explain the clinical significance of health status measures, Mayo Clin. Proc. 77 (2002) 371-383.

[68] D.E. Beaton, C. Bombardier, J.N. Katz, J.G. Wright, A taxonomy for responsiveness, J. Clin. Epidemiol. 54 (2001) 1204-1217.

[69] G.R. Norman, F.G. Sridhar, G.H. Guyatt, S.D. Walter, Relation of distribution- and anchor-based approaches in interpretation of changes in health-related quality of life, Med. Care 39 (2001) 1039-1047.

Available online at www.sciencedirect.com

science 